\title{
TRANSFORMASI SOSIAL-BUDAYA MASYARAKAT INDONESIA
}

\author{
Nurdien H. Kistanto \\ Fakultas Ilmu Budaya \\ Universitas Diponegoro \\ nhkistanto@gmail.com
}

\begin{abstract}
Social scientists have conceptualized several stages of sociocultural transformation as societal development. One version modified in this article constitutes a typology of preindustrial and industrial societies which consists of one, hunting \& gathering societies; two, pastoral societies; three, village agrarian societies; four, advanced traditional agrarian societies; and five, industrial societies; and six, postindustrial societies. To analyse the sociocultural transformation which happens in the Indonesian society, one has to observe and consider the long historical background which produces social heterogeneity. Thus, the direction and ideals of sociocultural transformation can be identified and conceptualized.
\end{abstract}

Key Words: sociocultural transformation, cultural dynamics, types of societies, Indonesian society.

\section{Pendahuluan}

Transformasi sosial-budaya dipahami sebagai perubahan besar dan menyeluruh dalam wujud dan karakteristik masyarakat, dari suatu keadaan ke keadaan lain sehingga menjadi lebih baik atau lebih maju. Ilmuwan sosialbudaya Rusia, Alexei N. Tarasov (2016) melihat transformasi sosialbudaya sebagai dinamika budaya (cultural dynamics); bersama dengan ilmuwan sosialbudaya Rusia lainnya, N. V. Shishova (2009), Tarasov menekankan bahwa, "Dynamics is an attribute characteristic of culture, which includes the entire set of changes that occur in it under the influence of internal and external factors; its analysis provides research funds, mechanisms and processes that describe the changes" (Tarasov, 2016; Shishova, 2009). Lebih lanjut Tarasov (2016) menerangkan,

"Thus, the cultural dynamics means any change, sustainable order of interaction of its constituent components, as well as a certain periodicity, stadial characteristic and the direction to any state. In this context, culture should be seen as a dynamic system, defining as a set of elements that are in relationship and connection with each other, which is form certain integrity, and which changes its status over time under the influence of external and internal forces. Analysis of the culture as a dynamic system shows that none of its element is a static entity. The philosophical concept or a religious doctrine, a masterpiece of world culture or scientific discovery - everything is the result of complex, long and contradictory process of development of the spiritual aspects of society, thus transforming and newly interpreting in the course of human development. Therefore, culture acts as an ambivalent connection of conservation, reproduction and constant renewal, and, consequently, the complexity, expressing it in a bizarre combination of traditional and innovative, conservative and modernizing, personal and social" (Tarasov, 2016: 11994). 
Para penjelajah, pedagang, dan misionaris yang dikirim ke berbagai tempat di dunia pada abad kejayaan penemuan oleh bangsa Eropa bertemu dengan bermacammacam masyarakat, sebagaimana disampaikan oleh antropolog Marvin Harris (1978: 13-14), seperti berikut.

Di beberapa wilayah seperti Australia, Kutub Utara (the Arctic), ujung selatan Amerika Selatan dan Afrika, mereka menemukan kelompok-kelompok manusia yang hidup mirip dengan nenek-moyang zaman batu Eropa kuno: rombongan dari duapuluh-tigapuluh orang, yang tersebar melintasi wilayah sangat luas, selalu bergerak, dan hidup sepenuhnya dengan berburu binatang dan mengumpulkan tanaman liar mereka para pemburu-pengumpul ini merupakan anggota-anggota dari species langka dan terancam punah (a rare and endangered species). Di wilayah-wilayah lain, seperti di hutan-hutan bagian timur Amerika Utara, hutan-hutan belantara Amerika Selatan, dan Asia Timur, mereka menemukan penduduk yang lebih padat yang menghuni desa-desa yang kurang-lebih permanen, dengan bertani dan terdiri dari satu atau dua struktur komunal, akan tetapi di sini pula senjata dan peralatan yang dipakai masih merupakan peninggalan prasejarah. Di tempat lain, para penjelajah tentunya juga menemukan pemerintah dan kerajaan yang sangat maju, dipimpin oleh raja dhalim dan kelas-kelas penguasa, dan dipertahankan oleh lasykar-lasykar yang siaga. Itulah kerajaankerajaan besar, dengan kota-kotanya, monumen-monumen, istana-istana, candicandi dan harta-kekayaan, yang telah memikat tokoh-tokoh seperti Marco Polo dan Columbus melintasi lautan dan padang pasir terlebih dahulu menuju negeri Cina, kerajaan terbesar dan canggih di dunia, yang para pemimpinnya memandang rendah 'para barbar bermuka merah,' para pemohon dari kerajaan-kerajaan yang lemah di luar batas dunia beradab. Dan ada pula India, tanah tempat sapi-sapi dimuliakan dan beban hidup yang berbeda dibagi secara adil menurut kebaikan tiap jiwa pada inkarnasi sebelumnya. Dan kemudian, ada pula pemerintahpemerintah dan kerajaan-kerajaan Amerika asli, dengan dunianya sendiri, masing-masing dengan seni-budaya dan agamanya yang berbeda, yaitu orang-orang Incas, dengan benteng-benteng batu yang besar, jembatanjembatan gantung, lumbung-lumbung yang penuh, dan perekonomian terkendali pemerintah; dan orang-orang Aztecs, dengan dewa-dewa haus darah yang disuapi hati manusia dan yang tak putus-putus mencari korban-korban segar (Harris, 1978; Giddens, 1991: 42).

Transformasi sosial-budaya sebagai dinamika budaya dalam peradaban masyarakat manusia meliputi proses yang lama dan bertahap-tahap, tidak selalu linear dan tidak selalu berjalan lurus dan lempang dari tahap ke tahap. Tahapan-tahapan dari transformasi ini kemudian menghasilkan tipologi masyarakat dengan wujud dan karakteristik kehidupannya. Transformasi sosialbudaya, dengan demikian, terjadi dari satu tahap ke tahapan yang lain, di satu waktu atau di waktu lain, di satu tempat atau di tempat lain, berlangsung tidak sama. M. Alan Kazlev (2009) menegaskan, "Included here is the evolution and transformation of society as a whole. This comes about through the influence of the totality of the individuals and communities, groups and movements within that society as a whole."

Para sosiolog telah menyederhanakan pemahaman transformasi sosial-budaya atau dinamika budaya (cultural dynamics) (Tarasov, 2016) atau evolusi dan transformasi (evolution and transformation) (Kazlev, 2009), yang menghasilkan tipologi masyarakat dalam tipe-tipe masyarakat pra- 
moderen atau pra-industrial dan tipe masyarakat moderen atau industrial (Lenski, 1966; Lenski \& Lenski, 1974; Ritzer, Kammeyer, Yetman, 1979; Vago, 1989; Giddens, 1991), seperti disampaikan berikut ini.

\section{Tipologi Masyarakat Praindustrial dan Industrial sampai Pascaindustrial}

Perubahan masyarakat manusia yang berlangsung dari zaman ke zaman melalui transformasi sosial-budaya telah menghasilkan terbentuknya 5 (lima) tipe masyarakat praindustri (preindustrial societies) dan industrial (industrial societies), sebagai berikut.

\section{1. Masyarakat Pemburu-Pengumpul} (Hunting \& Gathering Societies), terdiri dari segerombolan kecil orang-orang nomadik yang berpindah-pindah dan mengandalkan kehidupannya dari berburu binatang, menangkap ikan, dan mengumpulkan tanaman dan buah-buahan yang dapat dimakan; tak banyak perbedaan di antara anggota masyarakat dan antar masyarakat mereka; perbedaan tingkatan atau jabatan terbatas pada umur dan jenis kelamin, dengan laki-laki berburu binatang atau menangkap ikan, sedangkan wanita mengumpulkan bahan makanan dari tumbuh-tumbuhan; kelebihan personal yang dimiliki semata-mata berdasarkan ketrampilan dan kemampuan personal merupakan suatu bentuk keunggulan yang tak bisa secara sosial ditularkan kepada anak-anak keturunannya; mereka kira-kira hidup sejak 50.000 tahun yang lalu sampai tahun 7000 sebelum Masehi (Giddens, 1991: 54; Ritzer, 1979: 232; Lenski, 1966; Vago, 1989: 172), dan sekarang hampir punah (Giddens, 1991: 54).
2. 2. Masyarakat Penggembala (Pastoral Societies), yaitu masyarakat yang tergantung pada pemeliharaan binatang ternak untuk bahan makanan sendiri; jumlahnya antara beberapa ratus orang sampai ribuan orang; mereka ditandai oleh perbedaan khusus dan dipimpin oleh para kepala kelompok dan rajaraja perang; masa mulai hidupnya sama dengan masa hidup masyarakat pertanian desa, dan sekarang sebagian besar menjadi bagian dari pemerintahan masyarakat yang besar, dan cara-cara hidup tradisional mereka menuju kepunahan (Giddens, 1991: 54).

2. 3. Masyarakat Pertanian Desa (Village Agrarian Societies), menurut Giddens (1991: 54), merupakan masyarakat yang berbasis komunitas-komunitas pedesaan yang kecil, tanpa kota-kota dengan mata pencaharian utama bertani, dan sering ditambah dengan berburu binatang atau ikan dan mengumpulkan tanaman; ditandai dengan perbedaan yang lebih tajam daripada masyarakat pemburu dan pengumpul, dan dipimpin oleh para kepala (chiefs); mereka hidup sejak 12.000 tahun yang lalu hingga sekarang, dan sebagian besar sekarang menjadi bagian dari satuan politik dan pemerintahan sehingga kehilangan identitas khususnya. Sedangkan Ritzer (1979: 233-4) menyebut, masyarakat agrarian menguasai peradaban dari masa tahun 3000 sebelum Masehi hingga tahun 1800 sesudah Masehi, dengan tanah-tanah pertanian yang sangat luas dan tempat-tempat tinggal permanen sehingga menghasilkan panenan berlimpah yang dimungkinkan oleh inovasi teknologi seperti alat pertanian bajak yang secara efisien ditarik oleh hewan. Lenski (1966) juga mencatat terjadinya peningkatan produksi dan kelebihan pangan yang tajam dalam masyarakat pertanian ini sehingga mengalami kemajuan dalam transportasi, komunikasi, perteknikan, dan teknologi militer; demikian 
pula bentuk-bentuk baru dalam hubungan kekuasan muncul dalam wujud negara-kota, kekuasaan birokrasi, atau feudalisme sehingga sangat berkembang kelompok sosial dengan struktur dan stratifikasi sosial yang maju, unggul, turun-temurun, dan penyebabpenyebab perbedaan terutama bersifat ekonomik. Era masyarakat-masyarakat pertanian yang tercatat meliputi masyarakatmasyarakat Mesir kuno dan Cina, melampaui Abad Pertengahan hingga permulaan masyarakat industrial moderen; dalam era ini sistem kenegaraan tumbuh dan menjadi lembaga pusat (Ritzer, 1979: 233-4; Vago, 1989: 172).

\section{4. Masyarakat Pertanian Tradisional} Maju (Advanced Traditional Agrarian Societies), dalam masyarakat ini, pertanian masih merupakan andalan sistem ekonominya, akan tetapi kota-kota hidup sebagai pusat perdagangan dan produksi; sebagian pemerintahan masyarakat tradisional bisa sangat luas, dengan warga berjumlah jutaan orang, meskipun sebagian besar sangat terbatas dibandingkan masyarakat industrial yang besar sekarang ini; pemerintahan tradisional memiliki aparat pemerintahan khusus, dipimpin oleh raja atau kaisar, dengan perbedaan tingkatan-tingkatan di antara kelaskelas sosial yang berbeda-beda. Oleh Giddens (1991: 54-55) disebutkan, masyarakat tradisional telah hidup sejak 6.000 tahun sebelum Masehi sampai abad ke-19; sebagian besar pemerintahan tradisional atau bahkan semuanya sekarang punah; sedangkan Ritzer (1979) mengatakan bahwa masyarakat tradisional ini agaknya hidup sezaman dan bersamaan dengan masyarakat agrarian, namun sudah lebih maju karena masyarakat pertanian ini sudah mengembangkan kotakota sebagai pusat-pusat perdagangan dan produksi, sehingga dapat dikatakan sebagai masyarakat pertanian-tradisional atau tradisional pertanian kompleks dan maju, sebagai bagian dari masyarakat-masyarakat pra-industrial, yang sudah lanjut, atau maju (complex and advanced traditional agrarian societies).

\section{5. Masyarakat Industrial (Industrial} Societies), yang hidup pada zaman moderen, mulai tumbuh bersamaan dengan Revolusi Industri di Inggris yang berlangsung pada antara tahun-tahun 1760 dan 1830 (abad ke 18-19) (Ritzer, 1979) dan diwarnai dengan protes-protes keras berkesinambungan oleh masyarakat (Stearns, 1972). Masyarakat industrial moderen merupakan tipe masyarakat terakhir dalam transformasi sosial-budaya dan perkembangan peradaban masyarakat manusia, sebelum kemudian berkembang mulai akhir abad ke 20 tipe masyarakat pasca-industrial (postindustrial societies) dalam masyarakat pascamoderen (postmodern societies) (Bell, 1973). Kemajuan masyarakat industrial ditandai dengan dominasi kegiatan-kegiatan sosialbudaya dan ekonomi berbasis industri manufaktur atau pemrosesan atau pengolahan (manufacturing/processing industries).

\section{6. Masyarakat Pascaindustrial} (Postindustrial Societies), sesungguhnya adalah tahapan akhir dari masyarakat industrial, yang setidak-tidaknya berkembang mulai pada akhir abad ke-20 dan mencapai puncak kemajuannya pada abad ke-21. Selain dukungan manajemen dan teknologi sebagaimana dicapai oleh masyarakat industrial dengan aktivitas-aktivitas industri manufaktur, pemrosesan, pengolahan (manufacturing/processing industries), masyarakat pascaindustri pada abad ke-21 mengembangkan keunggulan teknologi informasi (information technology) yang meliputi teknologi keuangan (financial 
technology/fintech) dan teknologi media sosial (social media technology).

Sesungguhnya Ritzer (1979: 232-3), dengan mendiskripsikan kembali tulisantulisan Lenski (1966) dan Lenski \& Lenski (1974) menyelipkan satu tahapan masyarakat perkebunan atau pekebun (Horticultural Societies), di antara masyarakat pemburupengumpul (Hunting and Gathering Societies) dan masyarakat agrarian atau pertanian (Agrarian Societies), sebagai masyarakat yang, setidak-tidak-tidaknya sebagian, lebih menggantungkan hidupnya dari penanaman bahan makanan dan memelihara binatang, daripada dari berburu binatang dan mengumpulkan buah-buahan dan tanaman yang tumbuh liar untuk dimakan. Masyarakat ini, menurut Ritzer (1979: 233), hidup antara tahun-tahun 7000 sebelum Masehi sampai 3000 sebelum Masehi, sebelum tumbuh dan hidupnya masyarakat agrarian pada tahun 3000 sebelum Masehi sampai dengan 1800 sesudah Masehi, dan perubahan kebiasaan dari berburu dan mengumpulkan ke berkebun ini menandai penurunan kecenderungan untuk hidup secara nomadik yang berpindah-pindah dan menjadi awal dari komunitas-komunitas permanen, yang terdiri dari lebih banyak anggota yang menetap dan dapat memanen hasil kebun dalam jumlah lebih besar, dibandingkan komunitas-komunitas dari masyarakat pemburu dan pengumpul yang hidup berpindah-pindah.

Demikian pula Vago (1989: 172), yang menekankan pembahasan tentang dinamika hubungan kekuasaan (the dynamics of power relations) dari Lenski (1966), menyelipkan 2 (dua) tipe masyarakat di antara masyarakatmasyarakat yang, mengandalkan hidupnya dari, berburu binatang dan mengumpulkan hasil tanaman liar, dan masyarakatmasyarakat pertanian, yaitu masyarakatmasyarakat pekebun yang sederhana (simple horticultural societies) dan masyarakat- masyarakat pekebun yang maju (advanced horticultural societies). Dalam pembahasan Vago (1989: 172), masyarakat pekebun sederhana bercocok tanam dengan menggunakan alat tongkat untuk menggali (digging stick), sebagai alat paling sederhana dari perekonomian kebun (gardening economy) dan bercocok tanaman lebih dapat mengandalkan hasil kebun sebagai persediaan bahan pangan, yang pada gilirannya berhubungan dengan munculnya pembagian kerja (division of labor), termasuk dalam pengembangan pekerjaan spesialis bernilai ekonomis dan pekerjaan-pekerjaan penuh waktu dalam politik dan keagamaan. Spesialisasi fungsional ini pada waktunya melahirkan status-status sosial dan hubunganhubungan kekuasaan baru. Dalam masyarakat pekebun maju, peningkatan perbedaan status dan peran dalam masyarakat semakin bertambah, misalnya dengan berkembangnya alat kebun, cangkul, yang memungkinkan pemanfaatan tanah lebih besar dengan pengembangan pengkotak-kotakan kebun, pengairan, pupuk, atau metalurgi. Tahapan teknologi lebih tinggi mendorong peningkatan spesialisasi dalam kegiatan ekonomi dan pengembangan kekuasaan politik. Bersamaan dengan itu, terjadi perluasan status-status formal yang diikuti peningkatan hak atas kekayaan yang meliputi hak atas kepemilikan manusia, atau perbudakan, dan tersedianya aset-aset yang dapat dipindahkan seperti uang, hewan ternak, dan budak. Dari jurusan hubungan kekuasaan, tahapan pengembangan teknologi dan kemasyarakatan melahirkan lapisan sosial yang diperoleh secara turuntemurun secara tegas.

\section{Transformasi Sosial-Budaya dalam Masyarakat Indonesia}


$\begin{array}{lr}\text { Masyarakat } & \text { pascaindustrial } \\ \text { (postindustrial societies) } & \text { merupakan } \\ \text { kelanjutan dari masyarakat industrial (the } & \text { indvancement of industrial societies) yang }\end{array}$ berkarakteristik masyarakat penyedia industri jasa (service industry), dengan unggulan teknologi informasi (information technology), terutama teknologi keuangan (financial technology/fintech) dan teknologi media sosial (social media technology), selain berbagai teknologi peralatan-peralatan supercanggih (super-sophisticated equipment technology). Masyarakat industrial dan masyarakat pascaindustrial seperti di Indonesia, sesungguhnya berlatar belakang atau berbasis masyarakat pertanian dan perkebunan, bahkan meliputi masyarakat pemburu hewan, termasuk ikan dan pengumpul hasil tanaman dan tumbuh-tumbuhan liar, di darat maupun di laut, dan di udara, hingga saat ini.

Mempertimbangkan transformasi sosialbudaya dengan tahapan-tahapan yang dicapai dalam tipologi masyarakat pra-moderen dan moderen, agaknya masyarakat-masyarakat di wilayah kepulauan Indonesia pun mengalaminya, bahkan hingga sekarang semua tipe masyarakat tersebut masih hidup: sebagian seperti tipe-tipe masyarakat pemburu-pengumpul, seperti pemburu hewan di hutan dan semak-semak, dan nelayan tradisional tradisional, serta masyarakat pengumpul hewan dan penggembala dan pekebun, menjadi tipe peninggalan budaya di banyak wilayah yang maju maupun yang hampir punah; sebagian lagi seperti tipe-tipe masyarakat pekebun, masyarakat pertanian dan masyarakat tradisional, atau tipe masyarakat pertanian-tradisional atau tradisional-pertanian, atau pertaniantradisional-feodal, masih hidup dan berkembang, hidup bersama sebagai suatu entitas bangsa, yang hidup di wilayah-wilayah terpencil-pedalaman-terasing, di desa-desa, desa-desa-kota, di kota-kota kecil, bahkan di kota-kota besar dan metropolitan. Berbagai tipe masyarakat ini semua menjadi bangsa Indonesia.

Transformasi sosial-budaya bagi masyarakat-bangsa Indonesia harus diperlakukan, dibayangkan dan dicita-citakan secara khusus dengan mempertimbangkan latar-belakang historis yang sudah menjadi pengalaman bangsa dan latar budaya yang merupakan realitas yang dimiliki masyarakatmasyarakat di Indonesia dan sekitarnya, sehingga setidak-tidaknya 2 (dua) masalah sosial-budaya harus diperhatikan, sebagai berikut.

\section{1. Latar Belakang Historis}

Pertama, latar-belakang historis sebagai pengalaman bermasyarakat dan berbangsa yang berasal dari nilai-nilai dan kearifankearifan lokal dari kerajaan-kerajaan, yang tradisional agraris, maritim, feodal, yang dari zaman ke zaman mengalami dan menjalin pertemuan-pertemuan dan hubunganhubungan intensif, menerima, menyerap, dan mengamalkan nilai-nilai dan praktek-praktek kehidupan bersama dengan nilai-nilai dari luar, seperti India (sejak abad ke-1), dengan agama-agama dan nilai-nilai Hindu dan Budha, Cina (sejak abad ke-3) dan Kong $\mathrm{Hu}$ $\mathrm{Cu}$, dan Islam dan Timur Tengah (sejak abad ke-13), yang dilanjutkan dengan kolonial Eropa, Belanda (abad ke-17 sampai abad ke20). Pertemuan-pertemuan dan hubunganhubungan yang dibangun pada umumnya melalui perdagangan yang dilaksanakan atas kesepakatan bersama, yang dengan masyarakat India, Cina, dan Timur Tengah pada umumnya berlangsung secara damai; sedangkan dengan Eropa, Belanda diwarnai dengan kehendak untuk penguasaan, melalui agresi bersenjata, oleh bangsa Barat yang berekspansi dengan persiapan organisasi, peralatan dan persenjataan yang canggih, 
sehingga terjadi penjajahan dan penguasaan kegiatan-kegiatan ekonomi, politik dan pemerintahan, dengan strategi devide et empera (pecah-belah dan kuasai).

\section{2. Latar Budaya Heterogin}

Kedua, latar budaya sebagai realitas dengan nilai-nilai masyarakat kepulauan yang sangat heterogin, plural, multietnik, multilingual, multiras - sehingga disebut multikultural - berpaduan dengan realitas geografis (berkarakteristik alam daratan dan lautan), geopolitik (kawasan strategis dalam pergaulan antar bangsa dengan kepentingankepentingan politik dan ideologi), dan geoekonomi (berkarakteristik ekonomi, manajemen, dan matapencaharian agraristradisional-feodal). Latar budaya yang kompleks, rumit dan khas ini dapat menguntungkan jika upaya-upaya pengelolaannya tidak terganggu oleh sikap dan tingkah-laku warga masyarakat yang kontra-produktif dan mementingkan diri sendiri dan kelompok-kelompoknya.

\section{3. Arah dan Cita-Cita Transformasi Sosial-Budaya}

Mempertimbangkan masalah 2 (dua) latar tersebut, transformasi sosial-budaya masyarakat Indonesia menuju masyarakatbangsa yang dicita-citakan, dengan merumuskan format dan wujud budaya yang mampu dan efektif dalam menjawab tantangan sosial-budaya, ekonomi dan politik, dapat dibagi menjadi 2 (dua) arah dan tujuan, sebagai berikut.

\section{3. 1. Menjadi Negara-Bangsa Kesatuan yang Kuat}

Mentransformasikan bekas negara jajahan yang terpecah-pecah menjadi suatu negara-bangsa berbentuk Republik Kesatuan, yaitu negara-bangsa yang bersatu, kokoh-kuat, berdaulat, demokratis, dan moderen. Untuk mewujudkan ideal type, masyarakat dan negara yang dicita-citakan itu, bangsa Indonesia harus meneguhkan kembali akan kesadaran terhadap cita-cita bersama untuk menjadi negara-bangsa yang bersatu di atas realitas bhinneka tunggal ika, sebagai negara kesatuan yang didukung dan disangga oleh unsur-unsur yang berbeda sebagai "serat-serat budaya" bangsa (Kayam, 1989: 25). Modalmodal sebagai negara kesatuan telah dibangun oleh para pendiri dan pengembang bangsa yang merupakan hasil-hasil budaya bangsa moderen, seperti nama Indonesia yang indah dan tepat; Bahasa Indonesia sebagai bahasa nasional dan bahasa kesatuan dan pemersatu; Undang-Undang Dasar 1945 sebagai Konstitusi Negara dan payung hukum, dan Pancasila sebagai payung politik, hukum, dasar negara, nilai-nilai dan norma-norma luhur dan mulia. Dari modal-modal bangsa ini dapat dibangun sistem sosial-budaya nasional yang mewadahi kepentingan seluruh bangsa, dengan ketahanan bangsa dalam masyarakat yang sepenuhnya sadar dan bersedia berkorban untuk mewujudkan kesatuan nasional yang kokoh.

\section{3. 2. Menjadi Negara-Bangsa Industrial Moderen}

Mentransformasikan masyarakat dari status keterbelakangan sosial-budaya dan ekonomi agraris-feodal menjadi masyarakat industri moderen yang demokratis. Transformasi sosial-budaya ini mengandaikan suatu masyarakat yang bersedia menerima, mempelajari dan melaksanakan sistem nilai liyan yang akan diterapkan, yaitu sistem nilai industrial moderen yang menekankan rasionalitas, efisiensi, keterbukaan dan transparansi, sikap egaliter, demokrasi dengan 
kebebasan berpendapat, penghargaan terhadap hak azasi, dan persaingan sehat dan terbuka. Tahapan kesadaran sikap-mental kolektif yang dapat diterapkan untuk kegiatan ideal dan praktis dengan rajin dan tekun (industrious) bagi kemakmuran bangsa sangat penting sebagai modal dasar yang dikembangkan menuju masyarakat industri moderen berbasis kegiatan-kegiatan sosial-budaya ekonomi kreatif, produktif, dan inovatif dalam saranasarana industri manufacturing dan saranasarana pasca-industri jasa, menuju masyarakat yang kegiatan sosi-budaya dan perekonomiannya berbasis industri jasa, service industry, yang menjadi karakteristik postindustrial society, dalam sistem sosialbudaya pascaindustri, sociocultural postindustrial system.

\section{Simpulan}

Berbeda dari rumusan yang disusun oleh para sosiolog, transformasi sosialbudaya atau dinamika budaya (cultural dynamics) yang berlangsung dari zaman ke zaman di Indonesia tidak linear, tidak persis mengikuti tahapan-tahapan, sebagaimana tipologi perkembangan kebudayaan manusia dalam teks-teks sosiologi. Oleh sebab itu masyarakat-bangsa Indonesia sekarang ini terdiri dari semua tipe masyarakat yang pernah berada dan berkembang di Indonesia, jauh sebelum disebut Indonesia, mulai dari masyarakat pemburu-pengumpul bahan makanan di perairan, daratan dan udara, masyarakat pertanian, masyarakat industrial yang berbasis manufacturing, pembuatan atau pengolahan, dan masyarakat pascaindustrial, yang berbasis industri pelayanan (service industry), dengan teknologi, peralatan dan manajemen modern-rasional.

Pada saat ini masyarakat Indonesia di pusat-pusat kemajuan sudah belajar dan mulai terbiasa dengan nilai-nilai masyarakat industrial dan pascaindustrial tersebut; akan tetapi agaknya masih lebih banyak warga masyarakat, bahkan warga masyarakat elit, yang memahami dan melaksanakannya tanpa mengindahkan etika, norma, nilai-nilai baik dan hukum yang disepakati, dengan pelaksanaan yang kebablasan dan tak mencerminkan sikap masyarakat yang baik dan beretika, semisal yang berkembang dalam teknologi informasi, melalui programprogram media sosial. Kemajuan masyarakat menjadi masyarakat pascaindustri harus dibarengi dengan etika, norma-norma, dan nilai-nilai yang menghormati hak dan harapan manusia dalam masyarakat,

Transformasi sosial-budaya dalam masyarakat Indonesia dapat dipahami sebagai energi dan daya dorong bagi masyarakat Indonesia untuk dengan rajin dan tekun melakukan dan meningkatkan perubahan sosial-budaya dari suatu keadaan dan kehidupan masyarakat ke keadaan dan kehidupan masyarakat yang lebih baik, menuju kemakmuran dan kesejahteraan, melalui kegiatan-kegiatan hidup yang kualitasnya bertahap-tahap sesuai dengan tingkat peradabannya. Tahapan-tahapan dan tingkat-tingkat peradaban telah menjadi pengalaman bermasyarakat dan berbangsa dalam masyarakat-bangsa Indonesia, sehingga menjadi masyarakat-bangsa dalam tahapan sekarang ini yang menyiapkan dan mengembangkan diri di dalam pergaulan lokal-domestik-internal bangsa dan dalam pergaulan antar bangsa menuju pemantapan tahapan kualitas peradaban masyarakatbangsa berikutnya, bagi kemakmuran dan kesejahteraan masyarakat-bangsa yang bermartabat dan terkemuka sebagai khalifatullah di atas bumi manusia dan makhluk-makhluk ciptaan Allah Sang Pencipta, yaitu khalifatullah yang mengemban amanah untuk menjaga, melestarikan dan mengolah bumi, bagi kesejahteraan dan 
kebaikan dunia. Niat dan kehendak untuk membangun kebaikan dan kesejahteraan penting disampaikan karena kegiatan-kegiatan manusia sehingga mencapai tahapan-tahapan peradaban dengan peningkatan kualitasnya selalu dijalankan bagi kebaikan dan kesejahteraan manusia. Tanpa niat dan kehendak untuk meningkatkan kebaikan dan kesejahteraan manusia melalui kegiatankegiatan yang terus-menerus meningkat kualitasnya, manusia industrial moderen dan pascaindustrial, pascamoderen, mengalami kemunduran kualitas dan terperosok dalam jurang kekosongan dan kehancuran rohani dan jasmani, dengan tanda-tanda serakah terhadap alam, kekuasaan dan harta benda, arogan dan sewenang-wenang dalam kekuatan, dan menutup mata terhadap penderitaan dan nasib umat manusia.

\section{Daftar Pustaka}

Abercrombie, Nicholas, Stephen Hill, and Bryan S. Turner. 1988. Dictionary of Sociology. London: Penguin Books.

Bell, Daniel. 1973. The Coming of PostIndustrial Society: a Venture in Social Forecasting. London: Heinemann.

Breese, Gerald. 1966. Urbanization in Newly Developing Countries. Englewood Cliffs: Prentice-Hall.

Cambridge Advanced Learner's Dictionary, third edition, 2008. Cambridge: Cambridge University Press, p. 1548.

Crow, Ben, Mary Thorpe, et. al. 1988. Survival and Change in the Third World. Oxford: Polity Press.
De Jong, P. E. De Josselin. 1984. Unity in Diversity: Indonesia as a Field of Anthropological Study. Dordrecht, Holland: Foris Publications.

Geertz, Clifford. 1995. After the Fact: Two Countries, Four Decades, One Anthropologist. Cambridge: Harvard University Press.

Giddens, Anthony. 1991. Sociology. Oxford: Polity Press.

Harris, Marvin, 1978. Cannibals and Kings: The Origins of Cultures. London: Fontana.

Hart, Gillian, Andrew Turton, Benjamin White. 1989. Agrarian Transformation: local Processes and the State in Southeast Asia. Berkeley; University of California Press.

Harvey, Edward B. 1975. Industrial Society - Structures, Roles, and Relations. Georgetown, Ontario: The Dorsey Press.

Jary, David \& Julia Jary. 1991. Collins Dictionary of Sociology. Glasgow: HarperCollins.

Kayam, Umar. 1989. "Transformasi Budaya Kita," Pidato Pengukuhan Jabatan Guru Besar pada Fakultas Sastra Universitas Gadjah Mada, Yogyakarta, 19 Mei.

Kazlev, M. Alan. 2009. Social and Cultural Transformation. Kheper Home: Creative Commons License.

Kistanto, Nurdien H. August 1991. "Peasants, Civil Workers, and Industrial Workers in Java," SOJOURN, Vol. 6, Number 2 . 
Lenski, Gerhard E. 1966. Power and Privilege: A Theory of Social Stratification. New York: McGraw-Hill Book.

and Jean Lenski. 1974. Human Societies: An Introduction to Macrosociology, 2nd ed. New York: McGraw-Hill.

Moertono, Soemarsaid. 1985. Negara dan Usaha Bina Negara di Jawa Masa Lampau: Studi tentang Masa Mataram II, Abad XVI sampai XIX. Jakarta: Yayasan Obor Indonesia.

Nurdien H. K. Ed. 1983. Perubahan Nilai-Nilai di Indonesia. Bandung: Alumni.

Offe, Claus. 1976. Industry and Inequality. London: Edward Arnold.

Oxford Advanced Learner's Dictionary of Current English, 2000. Oxford: Oxford University Press, p. 1382.

Parker, S. R., et. al. 1981. The Sociology of Industry. London: George Allen \& Unwin.

Rabie, Mohamed. 2013. Saving Capitalism and Democracy. USA: Palgrave Macmillan.

Ramaswamy, E. A. 1981. Industry and Labour. Oxford: Oxford University Press.

Reading, Hugo F. 1977. A Dictionary of Social Sciences. London: Routledge \& Kegan Paul.

Ritzer, George, Kenneth C.W. Kammeyer, Norman R. Yetman. 1979. Sociology: Experiencing a Changing Society. Boston: Allyn and Bacon.
Schaefer, Richard T. 2004. Sociology Matters. Boston: McGraw-Hill.

Shanin, Teodor, Ed. Reprinted 1975. Peasants and Peasant Societies. Harmondsworth: Penguin Education.

Shishova, N. V. 2009. Kul'turologiya. Slovar'-spravochnik. Rostov-on-Don: Feniks. $596 \mathrm{p}$.

Stearns, Peter N. (Ed.). 1972. The Impact of the Industrial Revolution: Protest and Alienation. Englewood Cliffs: PrenticeHall.

Tarasov, Alexei N. 2016. "Theoreticalmethodological Bases of the Sociocultural Transformation" Concept Explication. International Journal of Environmental and Science Education Vol. 11, No. 18, 1199312003.

Triyono, Lambang dan Nasikun. 1992. Proses Perubahan Sosial di Desa Jawa: Teknologi, Surplus Produksi, dan Pergeseran Okupasi. Yogyakarta: FISIP UGM \& Rajawali Pers.

Vago, Steven. 1989. Social Change. Second edition. Englewood Cliffs: Prentice Hall.

Van Peursen, C. A. 1976. Strategi Kebudayaan. Yogyakarta: Kanisius \& Jakarta: BPK Gunung Mulia.

Wolf, Eric. 1966. Peasants. Englewood Cliffs: Prentice-Hall. 